\title{
Post-traumatic Intraorbital Foreign Object Tangential to the Intact Globe: An Unusual Location
}

\author{
Korhan Fazil, Gamze Ozturk Karabulut, Can Ozturker, Zehra Karaagac Gunaydin, Ebru Demet Aygit, \\ Muhittin Taskapili, Pelin Kaynak
}

University of Health Sciences Beyoglu Eye Training and Research Hospital, Istanbul, Turkey

\begin{abstract}
A 26-year-old woman with chronic irritation and infection of left upper eyelid and history of ocular trauma with unknown foreign object(s) was referred to oculoplastic clinic of our hospital. Multiple black micro foreign objects were seen in left upper eyelid skin, skin was edematous, fistula of the skin was present, and the globe was deviated inferiorly. On computerized tomography, multiple intraorbital foreign objects were observed at superior aspect of the orbita. Foreign object, $2 \times 1 \times 0.5 \mathrm{~cm}$ in size, localized tangentially to the globe with convex side facing intact eyeball, was surgically excised. Multiple metallic micro particles were also removed. The patient recovered well from injury within 6 months of surgery. Intraorbital foreign bodies may be mislocated in radiological imaging in trauma patients. Surgeon should always be alert for surprises during surgery on such patients.
\end{abstract}

Keywords: Foreign object, orbital trauma, skin fistula.

\section{Introduction}

Orbital foreign bodies are rare and can present various clinical features. Detecting orbital foreign body can be difficult, especially when the patient is referred to the hospital several months after the trauma (I).

\section{Case Report}

A 26-year-old woman with chronic irritation and infection of left upper eyelid and history of ocular trauma with unknown foreign object(s) was referred to oculoplastic clinic of the hospital. Eyelid wound suturation had been performed at an emergency service unit 6 months prior (Fig. I, 2).

In ophthalmic examination, best corrected visual acuity was $20 / 20$ and intraocular pressure was $16 \mathrm{mmHg}$, and biomicroscopical examination was normal. Multiple black colored micro foreign objects were observed in left upper eyelid skin, skin was edematous, fistula of the skin was present, and the globe was deviated inferiorly. On computerized tomography, multiple intraorbital foreign objects were seen at superior aspect of the orbita; however, evaluation was not optimal due to scattering. Excision of the foreign objects, fistulectomy, and exploration of left upper eyelid were planned.

During surgery, $2 \times 1 \times 0.5 \mathrm{~cm}$ foreign object localized tangentially to the globe with convex side facing the intact eyeball was excised. Multiple metallic micro particles were also removed. The patient's eyelid was nearly symmetrical to the other eyelid, and there was no swelling or hyperemia 6 months after the surgery (Fig. 3, 4).

\section{Conclusion}

Nearly every case of orbital trauma should be approached with high index of suspicion for penetrating injury with pos- 

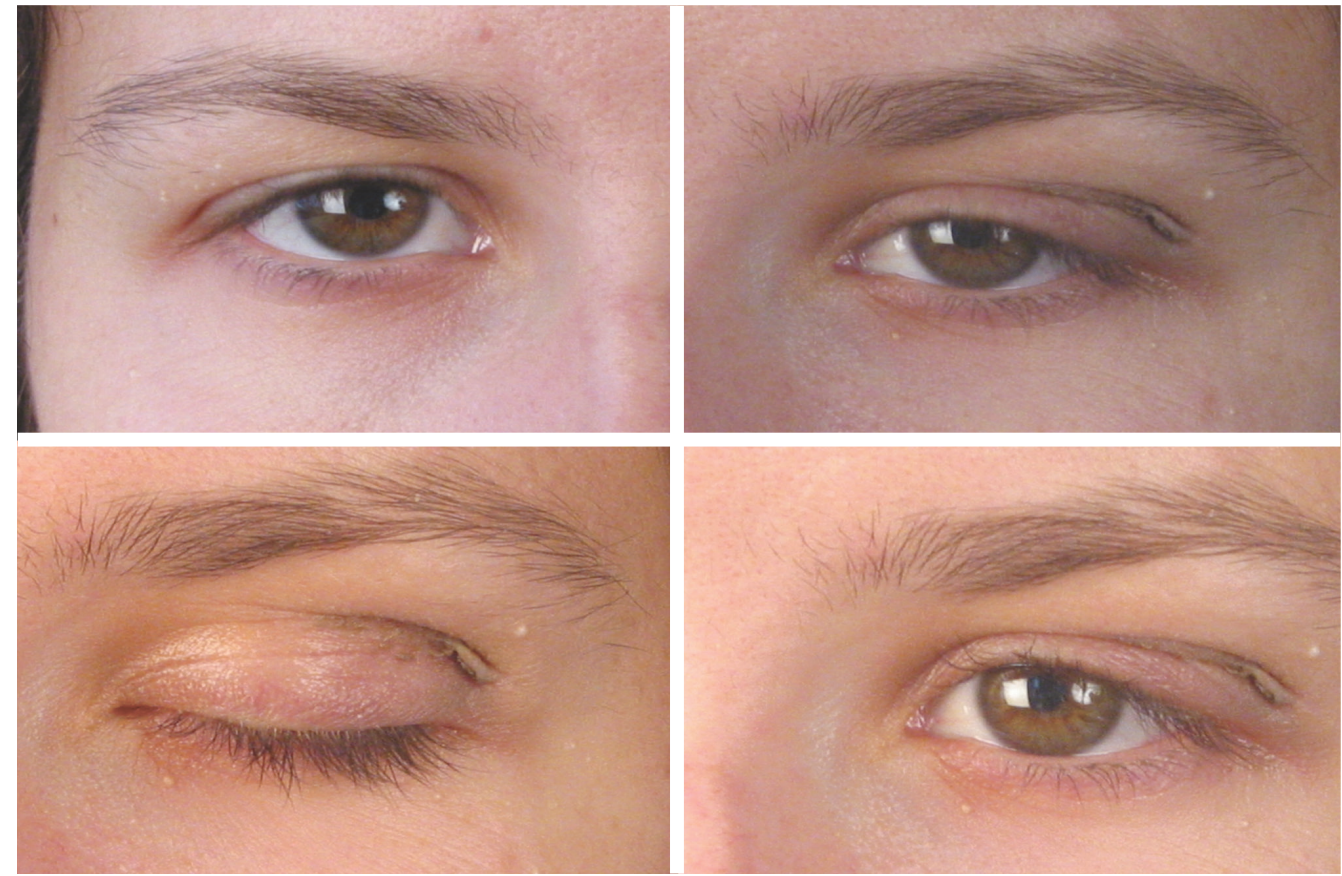

Figure I. Before operation.
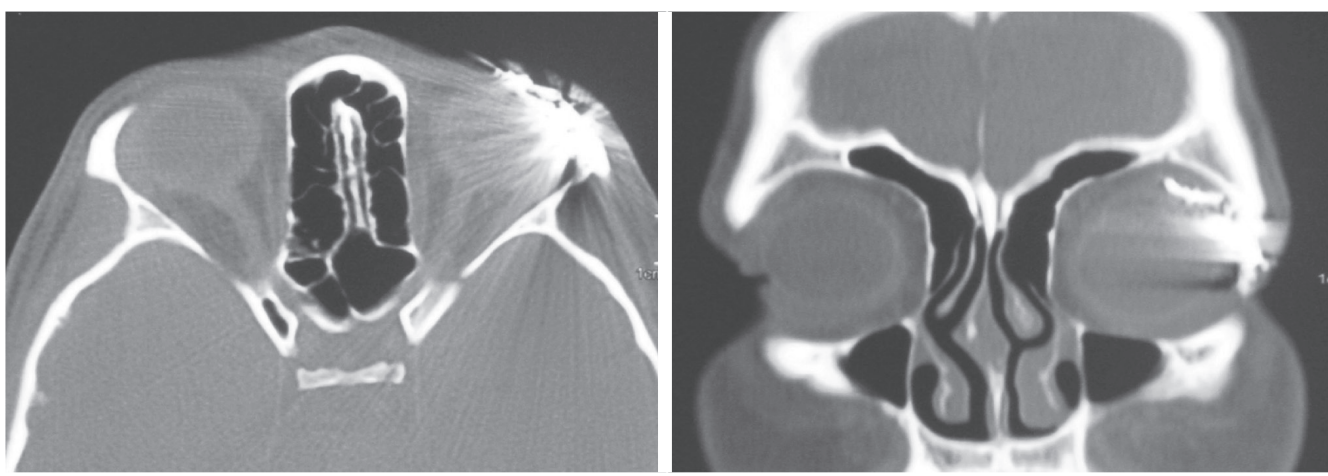

Figure 2. Preoperative radiological images.
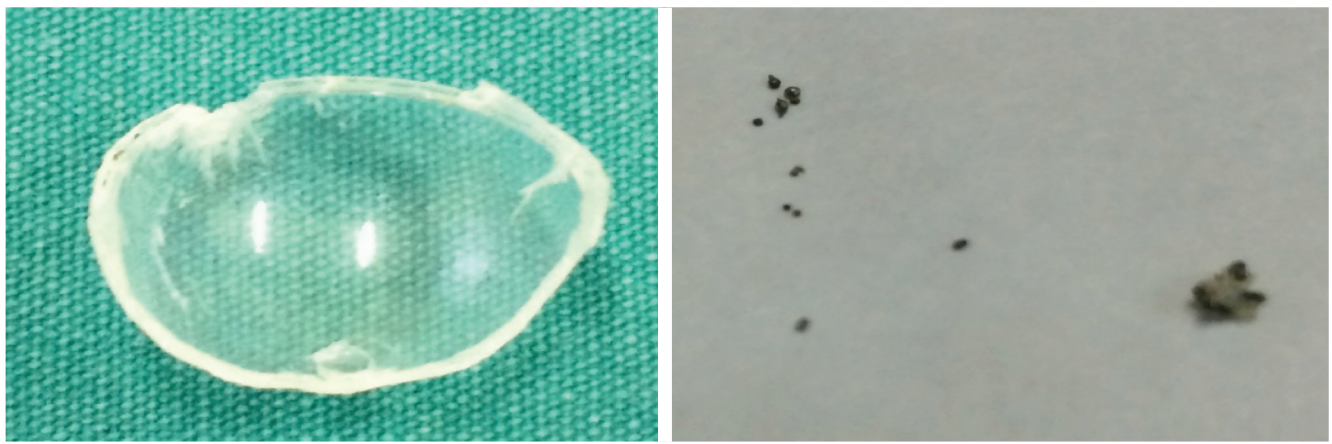

Figure 3. Excised foreign objects.

sible intraorbital foreign body. Various complications, such as granuloma, orbital cellulitis, orbital abscess, osteomyelitis, periosteitis, or chronic draining fistula may be seen after period of time ranging from days to years from initial penetrating trauma to the orbita (2). Baskararaian et al. reported 2 cases with chronic draining fistula I and 2 months after initial trauma (3). In our case, skin fistula developed 6 months after initial trauma.

Site and direction of trauma to the orbita are very important for protection of the eyeball. In our case, unusual 


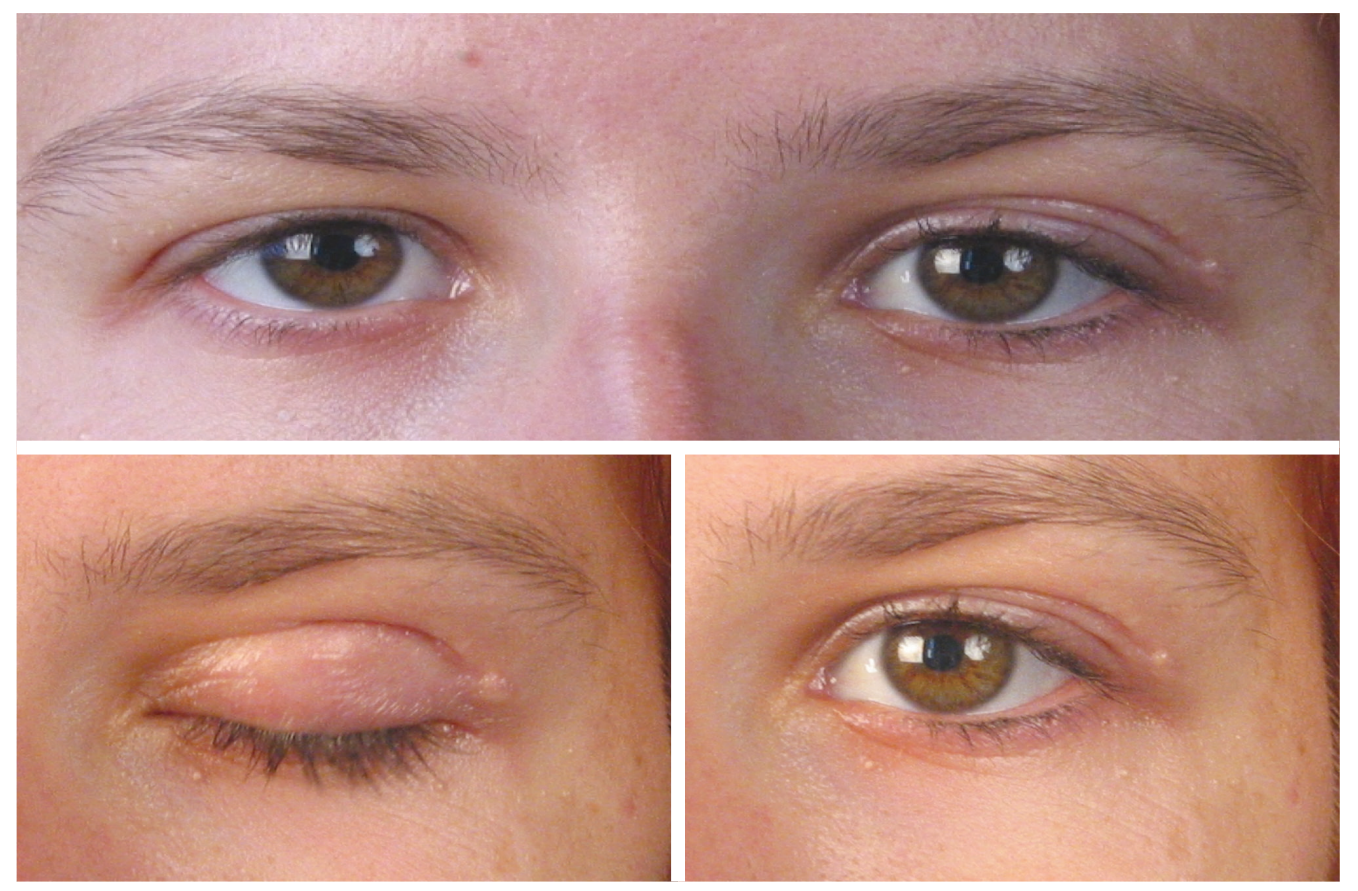

Figure 4. Six months after surgery.

position of the object itself protected the eyeball from penetrating injury.

Intraorbital foreign bodies may be mislocated in radiological imaging of trauma patients. The surgeon should always be alert for surprises during surgery on such patients.

\section{Disclosures}

Peer-review: Externally peer-reviewed.

Conflict of Interest: None declared.

Authorship Contributions: Involved in design and conduct of the study (KF, GOK, CO, ZKG, EDA, MT, PK); preparation and review of the study (KF, GOK, MT, PK); data collection (KF, MT,
PK); and statistical analysis (KF).

\section{References}

I. Prazeres S, Jacomet PV, Galatoire O, Lafitte F, Heran F, Boissonet $\mathrm{H}$, et al. Diagnosis and therapeutic management of an intraorbital organic foreign body. J Fr Ophtalmol 2009;32:8-15.

2. Karcioglu ZA, Nasr AM. Diagnosis and management of orbital inflammation and infections secondary to foreign bodies: a clinical review. Orbit 1998; 17:247-69. [CrossRef]

3. Baskararajan G, Danodarasamy M, Sivaramasubramanian P, Thiyagarajan S. Orbital foreign body-case reports. Indian J Ophthalmol 1982;30:53-5. 